\title{
Tudo ao Mesmo Tempo: Realidade ou llusão?
}

Everything at the Same Time: Reality or Illusion?

"Todo al Mismo Tiempo": ¿Realidad o Ilusión?
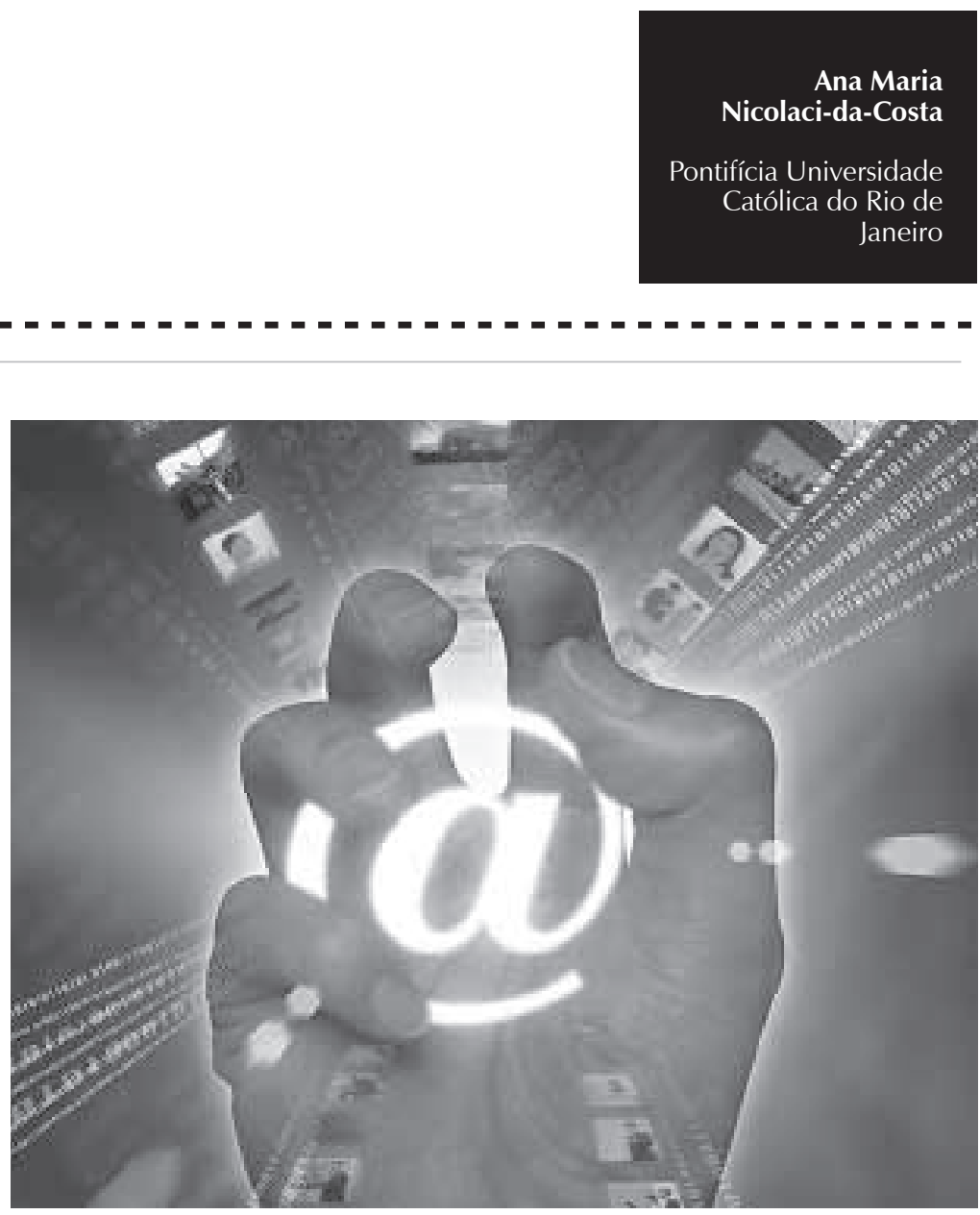
Resumo: Na modernidade, o tempo desempenhava um papel central. Hoje, o consenso é o de que esse papel cabe ao espaço. Apesar dessa unanimidade, no entanto, há muitas divergências quanto ao que caracteriza o espaço na atualidade. Tendo em vista que essas divergências se baseiam quase exclusivamente naquilo que os autores podem observar e não em resultados de pesquisa e também levando em consideração que alguns desses autores tendem a olhar para o mundo atual com olhos modernos, foi realizada uma pesquisa para examinar como o espaço é concebido por jovens. Os resultados revelaram que os participantes da pesquisa se percebiam circulando livremente por um espaço que já havia se tornado liso (sem fronteiras ou barreiras) tal como aquele descrito por Deleuze e Guattari. A mesma pesquisa também gerou resultados inesperados: permitiu examinar de perto uma dimensão temporal que ocupa lugar de destaque no mundo contemporâneo, a de simultaneidade. Tal exame, por sua vez, identificou a emergência de um novo conceito de simultaneidade que, associado ao emprego de algumas estratégias, torna possível para os jovens de hoje afirmar convictamente que são capazes de realizar várias tarefas ao mesmo tempo.

Palavras-chave: Espaço. Tempo. Contemporaneidade. Jovens.

Abstract: During modern times, time played a leading role. Nowadays, the consensus is that space occupies this key position. In spite of this unanimity, however, there is a lot of disagreement as to what characterizes space in our days. Given that most arguments are based almost exclusively on what the authors can observe and not on research results and also given that some of these authors still tend to observe the present world with modern eyes, research was conducted to inspect how young people conceive space. Results showed that those who participated in the research saw themselves circulating freely in a space that had already become "smooth" (without frontiers or barriers), such as that described by Deleuze and Guattari. The same research also produced unexpected results. It made possible to closely examine a temporal dimension which has become central in the present world: that of the "simultaneous" occurrence of a number of events. Such inspection, on its turn, revealed the emergence of a new concept of "simultaneity". Such a concept, associated with the employment of a few strategies, allows youngsters to say with conviction that they are able to perform several tasks "at the same time".

Keywords: Space. Time. Contemporary days. Youngsters.

Resumen: En la modernidad, el tiempo desempeñaba una función central. Actualmente, el consenso es el de que esta función le toca al espacio. A pesar de esa unanimidad, sin embargo, existen muchas divergencias en cuanto a lo que caracteriza el espacio en la actualidad. Teniendo en cuenta que esas divergencias se basan casi que exclusivamente en lo que los autores pueden observar, y no en resultados de investigación, y también llevando en consideración que algunos de esos autores tienden a mirar el mundo actual con ojos modernos, se ha llevado a cabo una investigación para examinar cómo el espacio es concebido por los jóvenes. Los resultados han revelado que los participantes de la investigación se sorprendían circulando libremente por un espacio que ya se había tornado "liso" (sin fronteras o barreras), exactamente como aquel descripto por Deleuze \& Guattari. La misma investigación también ha generado resultados inesperados. Ella ha permitido examinar desde cerca una dimensión temporal que ocupa lugar de destaque en el mundo contemporáneo: la de la "simultaneidad". Dicho examen, a su vez, ha identificado la emergencia de un nuevo concepto de "simultaneidad" que, asociado al empleo de algunas estrategias, vuelve posible que los jóvenes de hoy afirmen con convicción que son capaces de llevar a cabo varias tareas "al mismo tiempo". Palabras clave: Espacio. Tiempo.Contemporaneidad. Jóvenes.

Ao longo de séculos, a relação entre tempo e espaço foi percebida como relativamente estável. Espaço era aquilo que podia ser percorrido com maior ou menor rapidez por um ser humano ou um animal fazendo uso de suas próprias formas de locomoção; tempo, por sua vez, era aquilo de que se necessitava para realizar tal percurso. Além de utilizar as próprias pernas, o homem podia recorrer a outras fontes de energia. Estas, a exemplo da força animal ou de forças da natureza como ventos e correntes marítimas, tornavam o percurso mais rápido e/ou permitiam que distâncias maiores pudessem ser cobertas. O ser humano estava, contudo, restrito à exploração dessas fontes; não as podia controlar nem produzir.

A partir da virada do século XVIII para o XIX, com as sucessivas descobertas de fontes de energia inanimada (vapor, eletricidade, petróleo, etc.), cuja produção e utilização passou a poder controlar, o homem ganhou o comando do tempo, e a relação tempo- 
espaço foi profundamente alterada. Para dar somente alguns exemplos das consequências que tiveram, tais descobertas: (a) deram origem à implantação e disseminação do processo de industrialização, que aumentou vertiginosamente o ritmo da produção, (b) foram responsáveis pelo aparecimento de trens, automóveis e outros meios de transporte, cada vez mais rápidos, que reduziram o tempo necessário para qualquer deslocamento espacial, (c) possibilitaram a criação de novos meios de telecomunicação, como o telégrafo e o telefone, que permitiram o contato instantâneo entre pessoas geograficamente distantes.

Acima de tudo, essas mesmas descobertas foram responsáveis pelo surgimento de uma nova era - a modernidade - que teve a aceleração do tempo como uma de suas características mais proeminentes (Bauman, 2000/2001; Harvey, 1989/1999; Sennett, 1998/1999). Bauman chega a afirmar que “... a modernidade é, talvez mais que qualquer outra coisa, a história do tempo" (Bauman, 2000/2001, pp. 128-9).

Esse tempo moderno, ao qual Bauman faz referência, era um tempo diferente daquele imediatista que vigora hoje. Era um tempo longo, efetivamente dividido em passado, presente e futuro, um tempo no qual se usava a experiência passada (própria ou coletiva) para levar a cabo o planejamento de sequências de etapas com vistas a algum objetivo em um futuro distante (Bauman, 2000/2001; Harvey, 1989/1999; Sennett, 1998/1999). O presente era apenas um estágio de uma longa jornada. Já o espaço moderno, que servia de pano de fundo para o desenrolar desse tempo, era compartimentado de acordo com as funções específicas às quais se destinava. Tais compartimentos ou subdivisões, por sua vez, eram ciosamente separados uns dos outros por linhas divisórias, fronteiras ou barreiras. Tudo visava à manutenção de uma ordem, de uma hierarquia e de uma sequência temporal cuja finalidade era garantir o progresso (nunca de todo alcançado porque sempre remetido ao futuro).

Em meados da segunda metade do século XX, o avanço das tecnologias de telecomunicação (então ainda caracterizado primordialmente pela integração de diferentes pontos do mundo via satélite) permite a difusão da instantaneidade, ou seja, da aceleração limite do tempo (já atingida antes de forma restrita, como mencionado acima). Embora a instantaneidade só atinja seu ápice após o advento da internet e dos celulares, no final do século $X X$ e início do XXI, o tempo longo da modernidade perde sua supremacia. Cede lugar, segundo a literatura especializada de cunho pós-modernista ou de orientação sociotecnológica ${ }^{1}$ (Bauman, 2000/2001; Harvey, 1989/1999; Ling \& Yttri, 2002; Rheingold, 2003; Sennett, 1998/1999), ao presente imediato, porém contínuo, que flui de um instante a outro, e ao futuro de curto prazo que, muitas vezes, se confunde com esse presente contínuo. É inaugurado um novo período conhecido por várias de denominações: pós-modernidade, hipermodernidade, supermodernidade, modernidade líquida ou, simplesmente, contemporaneidade (Bauman, 1997/1998, 2000/2001; Harvey, 1989/1999; Jameson, 1991/1997; Nicolaci-da-Costa, 2005; Sennett, 1998/1999; Virilio, 1984/1999).

Nesse novo período (não importa o rótulo que receba), ocorre outra mudança radical na relação tempo-espaço. A instantaneidade congela o tempo, transforma-o em uma sucessão de momentos sempre presentes; já o espaço é libertado de seu confinamento moderno. As fronteiras e barreiras que separam seus inúmeros compartimentos são derrubadas, diluídas ou tornadas inoperantes por tecnologias que atravessam muros, superam obstáculos e ignoram fronteiras. 
É isso o que Jameson aponta ao argumentar que, tal como na esquizofrenia, atualmente todos vivemos boa parte de nossas vidas em um eterno presente no qual temos experiências múltiplas e fragmentadas. Como consequência, segundo ele, "nossa vida cotidiana, nossas experiências psíquicas, nossas linguagens culturais são hoje dominadas pelas categorias de espaço e não pelas de tempo, como o eram no período (...) do alto modernismo" (Jameson, 1991/1997, p. 43).

Nãoé, contudo, somente Jameson (1991/1997) que registra tais mudanças espaciais. Estas são objeto de registros recorrentes na literatura sobre o mundo de hoje (novamente, esteja essa literatura alinhada às teorias pósmodernas ou seja ela de origem sociotecnológica). Há, mesmo, um relativo consenso no tocante à supremacia das categorias espaciais sobre as temporais nos nossos dias (Nicolaci-da-Costa, 2005).

Esse relativo consenso, contudo, diz respeito exclusivamente à importância das categorias espaciais, isso porque o quadro que se apresenta no que concerne às configurações espaciais na contemporaneidade se mostra muito complexo, plural e confuso. Há muitas divergências sobre as características de diferentes tipos de espaço (sejam estes físicos, virtuais ou híbridos) bem como sobre o papel que desempenham na atualidade (Nicolaci-da-Costa, 2005, 2009).

De forma bastante resumida, pode-se dizer que essas divergências seguem duas tendências principais. A primeira, certamente oriunda de uma visão moderna, indica que está havendo multiplicação de arranjos espaciais na contemporaneidade, para a qual contribui o surgimento dos espaços gerados pelas novas tecnologias da informação e telecomunicação (TICs). Tal como acontecia na era moderna, essa multiplicação pressupõe separações por meio de diferentes tipos de fronteiras, barreiras e congêneres.
Já a segunda tendência, pós-moderna, alega que praticamente todas as formas de separação herdadas da era moderna estão sendo diluídas ou derrubadas com o auxílio das mesmas TICs que, como já foi dito, atravessa muros e supera obstáculos. Como resultado, a contemporaneidade seria caracterizada por aquilo que Deleuze e Guattari (1980/1997) chamaram de espaço liso, no qual nossa movimentação está se tornando cada vez mais fácil, ou fluida, para usar a terminologia de Bauman, (2001)

Tais visões conflitantes, aliadas ao fato de que, na maior parte das vezes, esses autores - todos eles socializados na modernidade (ou seja, na era pré-digital) ${ }^{2}$ - baseiam suas reflexões naquilo que podem observar, e não necessariamente em resultados de pesquisas, despertaram nosso interesse em investigar como os jovens de hoje, que já cresceram em um mundo pós-moderno e digital, veem esses múltiplos espaços.

Dito de outro modo, tendo em vista o quadro que se apresentava a partir do que dizem aqueles que pensam os espaços contemporâneos, nosso interesse residia em conhecer como percebem esses mesmos espaços aqueles que simplesmente sempre viveram neles. Do que estes se dão conta?

Em busca de respostas para essa pergunta, foi realizada uma pesquisa (Nicolaci-da-Costa, 2009) com jovens que, desde tenra idade, estão acostumados a circular constantemente por diversas vertentes de todas as três grandes categorias de espaço contemporâneas (físicos, virtuais e híbridos). O objetivo era o de, por meio de entrevistas abertas, fazer um levantamento das percepções que eles têm tanto do espaço físico quanto dos espaços pelos quais circulam ao fazerem uso das novas tecnologias de informação e comunicação, com as quais estão sempre muito familiarizados. 
Os resultados, já minuciosamente discutidos em Nicolaci-da-Costa (2009), revelaram que os participantes da pesquisa se percebiam circulando livremente por um espaço que já havia se tornado liso, como preconizavam Deleuze e Guattari (1980/1997). Nele não havia fronteiras, barreiras ou outras linhas divisórias a serem transpostas. Apesar desse alisamento, no entanto, eles claramente conheciam as especificidades de cada um deles. Tratava-se de um espaço liso, mas certamente não homogêneo, tal como aquele descrito por Deleuze e Guattari.

Para nossa surpresa, as revelações não pararam aí. Além de tornarem visíveis essas novas noções de espaço, os depoimentos coletados nessa pesquisa também permitiram examinar de perto uma dimensão temporal que ocupa lugar de destaque na contemporaneidade: a de simultaneidade. Tal exame, por sua vez, mostrou o que está por trás de um comportamento que é visto como característico dos jovens de nossos dias: a realização de várias tarefas simultâneas. Antes de apresentar esses últimos resultados, ainda não tornados públicos, faz-se necessário descrever, mesmo que brevemente, como foi realizada a pesquisa.

\section{A pesquisa}

Em todas as suas etapas, a pesquisa foi norteada pelos princípios e procedimentos do método de explicitação do discurso subjacente (MEDS), um método qualitativo especificamente elaborado para estudos exploratórios. No MEDS, a coleta de dados é feita principalmente por meio de entrevistas abertas em contextos informais (Nicolaci-daCosta, 2007). Tendo em vista que contextos informais existem tanto na vida real quanto na virtual, essas entrevistas podem ser levadas a cabo a partir de entrevistas face a face ou de entrevistas online (Nicolaci-da-Costa, Romão-Dias, \& Luccio, 2009). No caso desta pesquisa, foi feita a opção pelas últimas.

\section{Participantes}

O recrutamento dos participantes foi feito de acordo com os seguintes critérios: (a) todos deveriam ser estudantes com idades entre 18 e 25 anos, pois estes são usuários de praticamente todas as tecnologias disponíveis no mercado, (b) todos os jovens deveriam pertencer às camadas médias ou altas, porque o acesso a essas tecnologias pode ser dispendioso e (c) todos os participantes deveriam minimamente ter celular próprio e fazer uso de um computador residencial. Restrições a sexo ou profissão foram julgadas desnecessárias.

Com base nesses critérios, foram selecionados 20 jovens a partir de indicações de amigos e conhecidos. A todos foram atribuídos nomes fictícios para a preservação de seu anonimato. Sua média de idade era de 21 anos.

\section{Coleta de dados}

A coleta de dados foi realizada por meio de entrevistas individuais realizadas online (Nicolaci-da-Costa, Romão-Dias, \& Luccio, 2009) através do popular programa de bate-papo em tempo real MSN Messenger. O uso de entrevistas online apresentou duas vantagens: além de tornar a pesquisa interessante e natural para os participantes, permitiu que fossem investigados aspectos de seu uso de diferentes espaços que não poderiam ter sido levantados por meio de entrevistas presenciais convencionais. Os entrevistados demonstraram estar muito à vontade, pois estavam muito familiarizados com esse tipo de bate-papo. Tal como estipulado pelo MEDS, não houve qualquer solicitação para que alterassem sua rotina de conversa online (deixando de executar outras tarefas durante a entrevista, por exemplo).

Todas as entrevistas tiveram como base um roteiro estruturado construído especialmente 
para a pesquisa. Esse roteiro era composto por itens a partir dos quais deveriam ser formuladas as perguntas durante a própria entrevista de modo a preservar as características de conversas informais. Embora estruturado, o roteiro era usado de forma flexível durante as entrevistas, o que significa dizer que a ordem dos itens podia ser alterada de modo a manter o fluxo de associações do entrevistado.

O roteiro era dividido em duas partes. A primeira era composta de perguntas objetivas sobre cada um dos participantes, tais como: idade, o que estudava, há quanto tempo usava a internet e há quanto tempo usava celular.

Já a segunda parte era composta por itens/ perguntas de cunho mais investigativo e subjetivo. Esses itens se baseavam na observação dos hábitos que os jovens têm de usar, constante e, no mais das vezes, simultaneamente, diferentes tecnologias - interativas ou não - que lhes facultam o acesso a diferentes tipos de espaço. Intencionalmente, no entanto, nesses itens, nenhuma menção era feita a categorias espaciais. Queríamos investigar se estas surgiriam espontaneamente, o que indicaria que os entrevistados tinham consciência de seu trânsito por diferentes espaços.

Logo no início da entrevista, era solicitado que o entrevistado/a enviasse ao entrevistador (pelo próprio MSN ou por email) um print screen $^{3}$ da tela de seus computadores para que pudéssemos examinar quantas janelas estavam abertas para quais programas (ou ambientes). O print screen servia como disparador da entrevista.

Um print screen

é uma espécie de foto da tela do computador obtida pressionando a tecla Print Screen e posteriormente colando em outro ambiente como, por exemplo, no Word. necessário. Do roteiro, faziam parte 22 itens e vários subitens sobre o uso de diferentes tecnologias. A seguir, são listados alguns deles, especialmente relevantes para a presente discussão: (a) o que o entrevistado/a tinha em volta do computador; o que usava ao mesmo tempo em que o computador; (c) o que nunca usava ao mesmo tempo em que o computador; (d) em qual cômodo da casa estava, (e) onde estava seu celular; se tinha televisão por perto e se estava ligada; se o som estava ligado; se estava fazendo mais alguma coisa além de estar no computador; o que estava usando naquele momento no computador; se havia mudado alguma coisa desde o envio do print screen; (f) o que costumava usar ao mesmo tempo: computador, celular, telefone fixo, televisão, som, televisão, chat; como lidava com isso; (g) como se sentia fazendo várias atividades ao mesmo tempo no computador; (i) como se sentia fazendo várias atividades ao mesmo tempo fora dele; (j) com quantas pessoas costumava falar no MSN; caso o número variasse, a que se devia essa variação; naquele momento, com quantas pessoas estava falando além do entrevistador.

\section{Análise dos dados}

Todos os depoimentos foram salvos e copiados em arquivos do Microsoft Word para facilitar seu manuseio. Seguindo as técnicas do MEDS, primeiramente foi levada a cabo a análise interparticipantes, na qual todas as respostas de todos os entrevistados/as foram reunidas a partir dos itens/perguntas feitos. As respostas a cada item foram analisadas como um bloco. Desse modo, obteve-se uma visão de conjunto que possibilitou a identificação e a categorização das respostas recorrentes nos discursos dos entrevistados. Na segunda etapa - a da análise intraparticipantes foram examinadas as respostas de cada um em busca de possíveis inconsistências ou contradições reveladoras de algum discurso subjacente. Estas não foram encontradas. Nos 
depoimentos, havia somente os titubeios e reticências típicos de quem está falando sobre algo pela primeira vez. Assim sendo, os resultados abaixo têm como base somente a análise interparcicipantes.

\section{Resultados sobre a concepção de simultaneidade}

Uma leitura superficial nos teria levado à simples constatação daquilo que Tapscott (1997) já afirmava acontecer nos primórdios da difusão das tecnologias digitais e vem sendo mostrado repetidamente pela mídia e por outros pesquisadores (a exemplo de Palfrey \& Gasser, 2008): que crianças e jovens ficam entediados com facilidade e, por isso, gostam de fazer várias coisas simultaneamente.

Uma análise detalhada das tarefas que nossos entrevistados diziam executar ao mesmo tempo, no entanto, mostrou muito mais do que isso. Revelou claramente algumas estratégias e um novo conceito de simultaneidade que tornam possível o discurso das multitarefas simultâneas.

Cabe agora apresentar essa análise, que tem origem em uma releitura dos mesmos depoimentos que permitiram identificar as noções espaciais mencionadas acima. Para começar, serão descritas algumas características do contexto físico no qual as entrevistas foram realizadas.

\section{Contexto físico das entrevistas}

Praticamente todos os entrevistados concederam as entrevistas a partir de seus quartos, nos quais os computadores eram o centro das atenções. Segundo seus próprios relatos, nesses mesmos quartos, invariavelmente, havia muitas outras aparelhagens: impressoras, celulares, telefones fixos, equipamento de som, iPods, câmeras digitais e congêneres. A essas aparelhagens, misturavam-se livros para trabalhos de faculdade e objetos de todo o tipo, de ursinhos de pelúcia a camisinhas.

Nossa atenção estava concentrada no uso que faziam dos computadores e dos inúmeros aparelhos - interativos ou não - que podiam conectá-los a outros espaços físicos ou virtuais (e, por isso, foram batizados de aparelhos-portais; Nicolaci-da-Costa, 2009). Queríamos saber o que faziam online e com que frequência usavam os demais aparelhosportais, juntamente ao computador ou não. $\mathrm{O}$ fato de termos podido realizar as entrevistas enquanto os jovens estavam em seus próprios quartos fazendo aquilo que fazem rotineiramente (ou seja, enquanto usavam o computador e outros aparelhos disponíveis) provou ser muito produtivo. Como já foi dito, além da apreensão das noções espaciais apresentadas acima, tal procedimento de virtualmente entrar em seus quartos também facultou visualizar o que está por trás do discurso de que fazem tudo ao mesmo tempo, por eles constantemente repetido com convicção. Identificar como lidavam com toda essa parafernália tecnológica, contudo, exigiu que fossem estabelecidos alguns critérios de agrupamento, que irão organizar a exposição que se segue.

\section{O que faziam nos computadores}

Foram usadas duas fontes de informação sobre o que os participantes da pesquisa faziam nos computadores: os print screens solicitados no início das entrevistas e os depoimentos dos participantes ao longo destas. As informações coletadas a partir de cada uma dessas fontes serão discutidas separadamente.

(a) O que revelavam os print screens

Uma simples inspeção da barra de tarefas que aparecia nos print screens que nos foram 


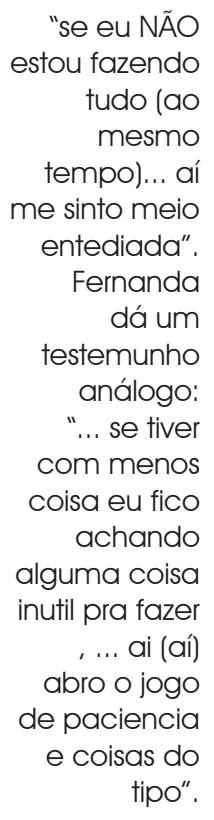

4 Todos os depoimentos serão reproduzidos exatamente como foram escritos pelos entrevistados. Estes, por sua vez, tiveram seus nomes mudados para preservação do anonimato. enviados já dava a dimensão do número de tarefas nas quais os entrevistados aparentavam encontrar-se engajados simultaneamente via computador. Sempre havia várias janelas abertas, a maior parte delas para programas interativos assíncronos, como o Orkut, ou síncronos, como o MSN Messenger. Também havia janelas abertas para documentos do Word, para o YouTube, para blogs, para o iTunes, para programas de download, etc... Examinemos alguns exemplos.

Durante a entrevista, segundo o print screen que nos enviou, Julia conversava com a entrevistadora e com outras duas pessoas no MSN. Além disso, tinha abertos o Orkut, o Outlook, um site, o Windows Media Player e o Word. Joy falava com cinco pessoas no MSN e tinha abertos o Orkut, o Word e o iTunes. Marcos tinha abertos o Windows Explorer, o Windows Media Player, um site e conversava com nove pessoas pelo MSN.

Esses exemplos mostram que, no mínimo, eles usavam ativamente o MSN para se conectar ao entrevistador e a vários outros interlocutores. Além disso, seus print_screens mostravam que também visitavam perfis do Orkut, usavam o Word ou o Power Point (provavelmente, para fazer trabalhos para a faculdade), viam vídeos no YouTube, ouviam música ou se engajavam em outras atividades.

(b) O que os entrevistados relatavam

O registro estático dos print screens não nos permitia diferenciar a importância que esses diversos programas tinham para os entrevistados e quais eles realmente usavam com frequência. Os relatos que os jovens fizeram, no entanto, mostraram claramente que o MSN Messenger tinha um peso muito maior do que todos os outros, De fato, o bate-papo online estava presente de forma destacada em todas as entrevistas, sendo a atividade predominante no uso que os participantes da pesquisa revelaram fazer do computador. Seguem-se bons exemplos.

Luciana diz que normalmente conversa com 4 ou 5 interlocutores "ao mesmo tempo". Já Marcos revela que fala com a média de 3 a 5 pessoas "simultaneamente", "mas pode ser 1 ou 7 ou mesmo 8 ...mas ai fica confuso e chato... dai eu deixo conversas morrerem ate voltar ao agradavel numero $3 " .{ }^{4}$

Para a maior parte dos entrevistados, fazer várias coisas simultaneamente no computador é mais do que a norma, é o desejável. Julia, por exemplo, diz: "se eu NÃO estou fazendo tudo (ao mesmo tempo)... aí me sinto meio entediada". Fernanda dá um testemunho análogo: “... se tiver com menos coisa eu fico achando alguma coisa inutil pra fazer , ... ai (aí) abro o jogo de paciencia e coisas do tipo".

Não é difícil perceber que esse fazer tudo ao mesmo tempo parece ter se tornado um valor positivo entre eles. É visto como uma capacidade inédita, por eles_desenvolvida, da qual se orgulham. Márcia Valéria dá um testemunho nesse sentido ao dizer que: “(nessa correria q é a nossa nos dias de hoje, temos que nos adaptar a fazer várias coisas ao mesmo tempo." Alguns admitem abertamente que tal capacidade os faz sentirem-se poderosos. É assim que Isabela se sente: "(no computador) pô.. parece q eu sou bem poderosa.. pq consigo fazer várias coisas ao mesmo tempo e nuan (não) deixar niguem esperando pra falar.. (ela obviamente se refere ao MSN) acho q sei administrar bem as minhas coisas.. nunca é demais.. igual coração de mãe sabe.. sempre cabe mais uma pessoas falando, ou mais um site.. sei lá...".

\section{Uso simultâneo do computador e de outros aparelhos}

No espaço de seus quartos, não é somente no computador que os entrevistados podem realizar atividades múltiplas. Diversos 
aparelhos-portais podem ser utilizados com o computador. Esse tipo de uso é aparentemente frequente, tanto que, quando perguntada sobre o que nunca usa ao mesmo tempo que o computador, Mariana chega a pensar um pouco antes de responder: "não sei...uso td (tudo) ao msm (mesmo) tempo... ja me acostumei... (é) como se eu estivesse fazendo uma só coisa".

Manter a televisão ligada enquanto usam o computador é um hábito comum entre os participantes da pesquisa. Rafael diz: "eu ligo o pc (computador) e ligo a tv ao msm (mesmo) tempo sempre". Marcos revela que, enquanto usa o computador, deixa a televisão ligada e fica "escutando programas de es porte,ou vendo jogo,... normalmente tem tv,pc e as vezes videogame ligado ao mesmo tempo...".

Já no que diz respeito aos celulares (ou telefones fixos), a maioria afirma que é difícil conjugar seu uso com o do computador (eles não parecem usar o recurso de viva-voz ou os fones de ouvido dos aparelhos celulares). Alguns, no entanto, se esforçam para superar esse obstáculo. Patrícia, por exemplo, revela conseguir usar o celular e o computador ao mesmo tempo, mas acrescenta que dói o pescoço. Rafael também diz que: "fica meio dificil de usar o mouse, o teclado e o celular ao msm (mesmo) tempo, afinal só tenho duas mãos...".

\section{Estratégias para fazer tudo ao mesmo tempo}

Outros entrevistados deram depoimentos muito mais detalhados tanto a respeito de seu uso do MSN quanto da utilização de aparelhos-portais concomitantemente ao computador. O conjunto desses depoimentos fez emergirem claramente as principais estratégias das quais esses jovens lançam mão para conseguir fazer tudo ao mesmo tempo. São elas: o estabelecimento de prioridades, a divisão da atenção e a alternância de tarefas. Examinemos cada uma delas.
Como já foi visto, são muitos os entrevistados que mantêm a televisão ligada enquanto usam o computador. Mariana está entre eles. Afirma que, para ver televisão e usar o computador ao mesmo tempo, ela tenta dividir a atenção e que estabelece prioridades de acordo com seu interesse imediato. Em suas próprias palavras: "tento dividir a atenção...mais (mas) o que ganha a atenção é o q mais interessar no momento." Luiza faz algo análogo: "a televisão eu vejo... olho pro computador quando alguém me chama pelo msn, por ex...". Enquanto isso, Alexandre explica o que faz. Diz: "agora estou respondendo uma pesquisa no msn e vendo o jogo do milan...rs... estou aki concentrado no msn mas ouvindo o jogo... se vejo q a entonação do narrador muda eh pq eh lance importante, aí paro e olho". Em outras palavras, eles dividem a atenção entre o computador e a televisão de acordo com prioridades que podem mudar de um momento para o outro.

Conjugar o uso de celulares ou telefones fixos (sem usar viva-voz) com o uso do computador é mais complicado. Como mencionado acima, alguns alegam que falam no celular enquanto digitam ou usam o mouse. Outros, no entanto, reconhecem que isso é quase impossível. Por isso, sem abandonar o discurso de que fazem tudo ao mesmo tempo, admitem que largam o computador temporariamente para falar no celular ou no telefone fixo. Alexandre fornece um bom exemplo. Diz: "normalmente qndo (quando) eu to no cel (celular) eu saiu (saio) do pc (computador),e qndo desligo retorno ... tel fixo,eu tbm (também) saiu do pc ...". Lucas faz o mesmo. Durante a entrevista, ele falava no MSN com a entrevistadora e com mais outras pessoas. O celular tocou e ele atendeu. A entrevistadora perguntou como conseguiu dar conta de tanta coisa. Ele respondeu: "fácil... parei tudo... atendi o cel... e depois retomei o MSN". E, assim, ele, inadvertidamente, revelou o uso da terceira estratégia mencionada acima: a alternância. 
Em verdade, essa espera desempenha um papel fundamental na arte de fazer tudo ao mesmo tempo. Eles estabelecem prioridades mutantes de acordo com seus interesses imediatos e, quando acontece um intervalo na comunicação (no caso do MSN) ou alguma tarefa online (uma página a carregar, um arquivo a baixar, uma foto a enviar) demora a ser concluída, alternam para outra atividade, porque não suportam

ficar parados esperando (Tapscott, 1997).
Alternar entre uma tarefa e outra é obviamente o que permite que esses jovens façam tantas coisas ao mesmo tempo, a exemplo de conversar simultaneamente com vários interlocutores no MSN. Os depoimentos de Lucas são bastante elucidativos, embora ele não demonstre ter consciência da alternância à qual recorre. Ele diz ser muito simples falar com várias pessoas ao mesmo tempo porque "a gente pode direcionar nossa atenção... (segundo um ou outro) criterio de preferência..." Alguns desses critérios ficam claros no diálogo que se segue.

Entrevistadora: "vc está fazendo mais alguma coisa além d estar no pc?"

Lucas: "Hm... vendo tv !"

Entrevistadora: "e tem alguém conversando com vc pessoalmente?"

Lucas: "ahh sim... minha mãe tava aqui no quarto agora a pouco." Entrevistadora: "e como vc fazia com a sua mãe, o pc e a tv?" Lucas: "Eu tirei os olhos da TV... e passei a prestar atenção nela ( minha mãe )... como ela não estava falando nada que eu considerasse útil... ela ficava com o tempo da tv... a espera por mensagens do pc (ou seja, do MSN)."

Em verdade, essa espera desempenha um papel fundamental na arte de fazer tudo ao mesmo tempo. Eles estabelecem prioridades mutantes de acordo com seus interesses imediatos e, quando acontece um intervalo na comunicação (no caso do MSN) ou alguma tarefa online (uma página a carregar, um arquivo a baixar, uma foto a enviar) demora a ser concluída, alternam para outra atividade, porque não suportam ficar parados esperando (Tapscott, 1997).

O interessante é que há uma disparidade entre o grau de consciência que eles demonstram ter dessas diferentes estratégias. As duas primeiras - o estabelecimento de prioridades e a divisão da atenção - são conscientes, dado que sobre ambas os entrevistados conseguiram dissertar com facilidade. O mesmo, contudo, não acontece no caso da alternância. Como Lucas, acima, eles deram indicadores claros de seu uso. Nenhum dos entrevistados, entretanto, fez menção explícita à alternância de tarefas,

\section{Discussão}

A ausência de menção explícita à estratégia de alternar tarefas sugere que os entrevistados dela não tinham consciência, diferentemente do que acontecia no caso do estabelecimento de prioridades e da divisão de atenção. Tal falta de consciência, por sua vez, é provavelmente uma consequência da combinação de três fatores principais. São eles: (a) a confusão existente no que diz respeito ao significado de multitarefa, (b) a mitologia de poderes especiais da chamada geração multi e (c) uma nova concepção de simultaneidade que incorpora à capacidade humana de dividir a atenção a capacidade do computador de simular a execução de tarefas alternadas como se fossem simultâneas. Esses três pontos serão discutidos abaixo.

\section{As origens da concepção de multitarefa e as imprecisões geradas por sua difusão}

Nos primórdios do desenvolvimento dos computadores, o tempo de uso da unidade central de processamento (CPU) era caro, e os equipamentos periféricos (que continham, por exemplo, os dados a serem inseridos no computador), muito lentos. Assim sendo, a CPU tinha que parar a execução de uma tarefa quando os periféricos (como as leitoras de cartão ou de fitas magnéticas) estavam em uso.

Para otimizar o aproveitamento da CPU, na década de 1960, foram criados os primeiros sistemas operacionais multitarefa (Mounima, s/d). Então, diferentes programas em batelada (batch) eram colocados em fila na memória 
do computador para serem executados. Enquanto um deles usava um periférico, outro passava a ser processado pela CPU. O procedimento continuava, de forma alternada, até que todos os programas da fila fossem completamente executados.

O tempo passou, e os sistemas operacionais multitarefa se difundiram juntamente aos computadores. O termo multitarefa se tornou tão conhecido que passou a constar de vários dicionários gerais, como, entre outros, o Dicionário Aurélio - Século XXI (Ferreira, 1999) e o Dicionário Aulete Digital (2010), sempre definido tendo os computadores como referência. Examinemos o que dizem esses dois dicionários.

No Aurélio, o verbete multitarefa é definido como "relativo à capacidade que têm alguns sistemas operacionais de simular o processamento simultâneo de mais de uma tarefa, graças à divisão do tempo do processador entre elas". Já no Aulete, o mesmo verbete tem outra definição: a "capacidade que tem um sistema operacional de computador de executar mais de um programa simultaneamente".

Tomando como base as definições dadas por esses dois dicionários, já podemos detectar o potencial de confusão que o termo multitarefa tem. Sem sairmos do domínio da computação, podemos afirmar que, no caso de uma única CPU, a definição dada pelo Aurélio (1999) está correta, e aquela oferecida pelo Aulete (2010), equivocada, isso porque, quando existe uma única $\mathrm{CPU}$, duas tarefas não podem ser executadas ao mesmo tempo, mas somente ser intercaladas para melhor aproveitar a capacidade da unidade central de processamento como vimos acima. Isso apenas gera a ilusão de processamento simultâneo de mais de uma tarefa.
Vejamos agora o que diz a Wikipedia que, diferentemente desses dois dicionários gerais, tem seus verbetes sempre definidos por usuários de computadores e da internet na qualidade de contribuintes anônimos. Em sua versão em inglês (http://en.wikipedia.org), encontramos outra gradação de significado, dado que o termo multitarefa é expandido para abarcar comportamentos humanos. É feita uma diferença entre computer multitasking (multitarefa referida ao computador) e human multitasking (multitarefa referida a seres humanos). Computer multitasking é definida como "a execução aparentemente simultânea de duas ou mais tarefas pela unidade central de processamento de um computador" (minha tradução e minha ênfase). Já human multitasking recebe uma definição diferente: "a habilidade que uma pessoa tem de executar mais de uma tarefa ao mesmo tempo" (minha tradução). Em outras palavras, a Wikipedia registra que seres humanos têm a capacidade de fazer mais de uma coisa ao mesmo tempo, e que computadores com uma única CPU dão somente a ilusão de executar mais de uma tarefa simultaneamente.

\section{A popularização do conceito de multitarefa e o mito de uma geração com super- poderes}

Ao sair do campo semântico da informática e passar a ser aplicado ao comportamento de seres humanos, o termo multitarefa acabou se tornando cada vez mais impreciso. Nesse processo de popularização, o slogan de lançamento do sistema operacional Windows 95 certamente desempenhou um importante papel. Lembremo-nos do que dizia a propaganda, amplamente veiculada para a população em geral em jornais e revistas da época: o slogan era Assobiando e chupando cana. A ele se seguia o seguinte texto: “Com Windows 95, a multitarefa no seu PC ficou muito mais fácil. Agora você pode imprimir enquanto você escreve um texto, 
enquanto você roda um velho programa em DOS, enquanto você navega pela internet, enquanto você faz o que quiser" (Nicolacida-Costa,1998, pp. 49-50).

Uma vez absorvida, a noção de que é possível fazer o impossível - assobiar e chupar cana ao mesmo tempo - ganhou autonomia e passou a ser empregada não mais exclusivamente a computadores, mas principalmente em relação aos jovens usuários de tecnologias digitais. A mídia foi uma das grandes responsáveis por isso. Vejamos alguns exemplos relativamente recentes de algo que já vem sendo feito há alguns anos.

Em 3 de outubro de 2006, a revista Megazine, do jornal $O$ Globo, exibia uma matéria de capa na qual aos jovens eram atribuídas capacidades inéditas. O título era Geração Multi. Logo após, um texto explicativo afirmava: "Multifuncionais, multifocais e multimídia, eles (os jovens) são capazes de estudar e, ao mesmo tempo, ver TV, ouvir música e bater papo no MSN" (minha ênfase).

Uma reportagem da revista VEJA de 6 de agosto de 2008 (pp. 92-93) tinha um título ainda mais radical para abordar o mesmo tema. Lia-se: "Tudo ao mesmo tempo - e agora". Novamente, um pequeno texto explicativo dizia: "Pelo computador e pelo celular, as crianças conversam com vários amigos, jogam videogame e ainda discutem com os pais. Agora você pelo menos sabe o nome disso: seu filho é multitarefas."

Ambas as matérias eram ilustradas por fotos glamurosas de jovens sorridentes, cercados de aparatos tecnológicos de última geração, aparentando fazer uso de todos simultaneamente. Todas as fotos passavam a imagem de jovens dotados de superpoderes. O mito nelas ganhava concretude.

\section{A simultaneidade na era dos superpoderes da geração multi}

Palavras têm origem em contextos específicos. Quando esses contextos sofrem transformações, seus significados também podem mudar. Hobsbawn (1962/2006) já chamava a atenção para esse fenômeno no que diz respeito às consequências da Revolução Industrial. Nicolaci-da-Costa (2009) vem fazendo o mesmo em relação à Revolução Digital, já tendo identificado vários deslizamentos semânticos que resultam em novos significados para palavras de uso corriqueiro.

A palavra multitarefa nasceu no contexto da computação e, nesse contexto, tinha um significado específico. Um sistema operacional multitarefa alternava a execução de duas ou mais tarefas até que todas chegassem ao fim; assim sendo, tinha-se a ilusão de que haviam sido executadas simultaneamente.

Ao se transformar em uma palavra de uso geral, cuja definição consta de dicionários não especializados, seu significado já começou a ser objeto de equívocos, como o do Dicionário Aulete Digital (2010) anteriormente citado. Sua progressiva popularização só fez aumentar a confusão, já anunciada por esse dicionário, ao associá-la cada vez mais intimamente à concepção de tarefas executadas simultaneamente por seres humanos, mesmo que isso seja impossível como "assobiar e chupar cana ao mesmo tempo".

Ao sugerir que isso é possível, a mídia passa a ideia de que os jovens que pertencem à geração multi são dotados de superpoderes. Os jovens se identificam com essas insinuações e os mais velhos parecem aceitá-las, dada a sua surpresa diante de tantas novidades com as quais muitas vezes são incapazes de lidar (ou com as quais lidam lentamente). 
Como consequência, podemos observar que vem ocorrendo mais um deslizamento semântico. Emerge uma nova concepção de simultaneidade associada ao conceito de multitarefa, concepção essa que incorpora à capacidade humana de dividir a atenção a capacidade do computador de simular a execução de tarefas alternadas como se fossem simultâneas. Em outras palavras, a ilusão de simultaneidade possibilitada pela alternância de tarefas é transformada em simultaneidade real no imaginário contemporâneo. Tal como na propaganda do Windows 95, o impossível se tornou possível.

\section{Ana Maria Nicolaci-da-Costa}

Doutora em Psicologia pela Universidade de Londres. Professora Associada da Pontifícia Universidade Católica do Rio de Janeiro, Rio de Janeiro - RJ - Brasil.

E-mail: anicol@puc-rio.br

Endereço para envio de correspondência:

Pontifícia Universidade Católica do Rio de Janeiro - Departamento de Psicologia

Rua Marquês de São Vicente 225, Gávea Rio de Janeiro, RJ - Brasil. CEP 22543-900 


\section{Referências} Lexikon/Odisséia Recuperado em 6 de junho de 2010 de http://www.auletedigital.com.br.

Bauman, Z. (1998). O mal-estar da pós-modernidade (M. Gama, \& C. M. Gama, trad.). Rio de Janeiro: Jorge Zahar (Trabalho original publicado em 1997).

Bauman, Z. (2001). Modernidade líquida (P. Dentzien, trad.). Rio de Janeiro: Jorge Zahar (Trabalho original publicado em 2000).

Deleuze, G., \& Guattari, F. (1997). Mil platôs: capitalismo e esquizofrenia (vol. 5, P. P. Pelbart, \& J. Caiafa, trad.). São Paulo: Editora 34 (Trabalho original publicado em 1980).

Ferreira, A. B. H. (1999). Dicionário Aurélio Eletrônico: Século XXI. Versão 3.0. Rio de Janeiro: Nova Fronteira / Lexikon Informática Ltda.

Harvey, D. (1999). Condição pós-moderna (A. U. Sobral, \& M S. Gonçalves, trad.). Rio de Janeiro, Loyola (Trabalho original publicado em 1989).

Hobsbawn, E. J. (2006). A era das revoluções: Europa 1789-1848. (M. T. Lopes Teixeira, \& M. Penchel, trad.). São Paulo: Paz e Terra (Trabalho original publicado em 1962).

Jameson, F. (1997). Pós-modernismo: a lógica cultural do capitalismo tardio (M. E. Cevasco, Trad.). São Paulo: Ática (Obra original publicada em 1991).

Ling, R., \& Yttri, B. (2002). Hyper-coordination via mobile phones in Norway. In J. E. Katz, \& M. Aakhus (Orgs.), Perpetual contact: Mobile communication, private talk, public performance (pp. 139-169). Cambridge: Cambridge University Press.

Mounima, A. (s/d). History of operating systems. Recuperado em 4 de junho de 2010 de http://www.computinghistorymuseum. org/teaching/papers/research/history_of_operating_system_ Moumina.pdf
Nicolaci-da-Costa, A. M. (1998). Na malha da rede: os impactos íntimos da internet. Rio de Janeiro: Editora Campus.

Nicolaci-da-Costa, A. M. (2005). O cotidiano nos múltiplos espaços contemporâneos. Psicologia: Teoria e Pesquisa, 21(3), 365-373.

Nicolaci-da-Costa, A. M. (2007). O campo da pesquisa qualitativa e o método de explicitação do discurso subjacente (MEDS). Psicologia: Reflexão e Crítica, 20(1), 65-73.

Nicolaci-da-Costa, A. M., Romão-Dias, D., \& Luccio, F. Di. (2009). $\mathrm{O}$ uso de entrevistas on-line no método de explicitação do discurso subjacente (MEDS). Psicologia: Reflexão e Crítica, 22(1), 36-43.

Nicolaci-da-Costa, A. M. (2009). Quando o velho esconde o novo: antigas palavras, novos significados. Psicologia: Teoria e Pesquisa, 25(1), 109-117.

Palfrey, J., \& Gasser, U. (2008). Born digital: Understanding the first generation of digital natives. New York: Basic Books.

Prensky, M. (2001), Digital natives, digital immigrants. On the horizon, MCB University Press, 9(5), 1-6. Recuperado em 7 de dezembro de 2008 de http://www.twitchspeed.com/ site/Prensky\%20-\%20Digital\%20Natives, \%20Digital\%20 Immigrants\%20-\%20Part1.htm,

Rheingold, H. (2003). Smart mobs: The next social revolution. Cambridge, Mass.: Perseus Books.

Sennett, R. (1998). The corrosion of character: The personal consequences of work in the new capitalism. New York: WW. Norton and Company.

Tapscott, D. (1997). Growing up digital: The rise of the net generation. New York: McGraw-Hill.

Virilio, P. (1999). Espaço crítico. Rio de Janeiro: Editora 34 (Obra original publicada para trabalho original publicado em 1984). 